\title{
Removal of benzene and toluene by carbonized bamboo materials modified with $\mathrm{TiO}_{2}$
}

\author{
Chih Shen Chuang ${ }^{\mathrm{a}}$, Ming-Kuang Wang ${ }^{\mathrm{b}}$, Chun-Han Ko ${ }^{\mathrm{a}, *}$, \\ Chia-Chih $\mathrm{Ou}^{\mathrm{c}}$, Chien-Hou Wu ${ }^{\mathrm{d}}$ \\ ${ }^{a}$ School of Forestry and Resource Conservation, National Taiwan University, Taipei 106, Taiwan \\ ${ }^{\mathrm{b}}$ Department of Agricultural Chemistry, National Taiwan University, Taipei 106, Taiwan \\ ${ }^{\mathrm{c}}$ Department of Material and Chemicals Engineering, National University of Kaohsiung, Kaoshiung 811, Taiwan \\ d Department of Biomedical Engineering and Environmental Sciences, National Tsing-Hwa University, Hsin-Chu 300, Taiwan
}

Received 5 November 2006; received in revised form 8 March 2007; accepted 8 March 2007

Available online 24 April 2007

\begin{abstract}
Carbonized moso bamboo (Phyllostachys pubescens) was coated with $\mathrm{TiO}_{2}$ nanoparticles to enhance its removal efficiency of harmful gases. Carbonized bamboo- $\mathrm{TiO}_{2}$ composite $(\mathrm{CBC})$ was prepared by heating mixtures of carbonized bamboo powder $(\mathrm{CB})$ and $\mathrm{TiO}{ }_{2}$ nanoparticles, denoted as $\mathrm{CBM}$, under nitrogen condition. $\mathrm{TiO}_{2}$ nanoparticle and carbonized bamboo powder were mixed with the mass ratios of $1 / 1$ and $2 / 1$, respectively. At the same mass ratio of $\mathrm{TiO}_{2}$ to $\mathrm{CB}$, the benzene and toluene removal efficiencies follow the trend: $\mathrm{CBC}>\mathrm{CBM}>\mathrm{CB}$, which is consistent with the amount of $\mathrm{TiO}_{2}$ validated by elemental analysis. Sorption mechanism of benzene and toluene by $\mathrm{CB}, \mathrm{CBM}$ and $\mathrm{CBC}$ might belong to hydrophobic-hydrophobic interaction, observed by depletion of untreated bamboo (UB) carbohydrates during carbonization. Sorption kinetics was further analyzed, and optimal correlation was found by fitting with the Elovich kinetic equation.
\end{abstract}

(c) 2007 Elsevier Ltd. All rights reserved.

Keywords: Benzene; Toluene; Carbonized moso bamboo; Elovich equation; $\mathrm{TiO}_{2}$ nanoparticles

\section{Introduction}

Charcoals from biomass are popular adsorbents for air and water purification (Mor et al., 2006; Sarin and Pant, 2006). Recently, bamboo charcoal has been widely applied as well (Mizuta et al., 2004) with moso bamboo (Phyllostachys pubescens) being recognized as one of the most popular biomaterials for air purification (Asada et al., 2002). $\mathrm{UV} / \mathrm{TiO}_{2}$ systems are also widely employed for removing volatile organic compounds (Wang et al., 2003; Dagaonkar et al., 2003). UV/ $\mathrm{TiO}_{2}$ combined with wood charcoal (Doi et al., 2000) and commercial activated carbon (Ao and Lee, 2004) possess greater efficiencies in removal of gaseous organics than those of unmodified materials. Similar find-

\footnotetext{
* Corresponding author. Tel.: +88623366 4615; fax: +886223654520.

E-mail address: chunhank@ntu.edu.tw (C.-H. Ko).
}

ings were widely reported for aqueous organics (Qourzal et al., 2004). However, the modification of $\mathrm{TiO}_{2}$ on carbonized moso bamboo and its enhanced air purification capabilities has not been reported yet.

In this study, $\mathrm{TiO}_{2}$ nanoparticles were firstly synthesized by the sol-gel process, then coated on carbonized moso bamboo powder (CB) surface to produce the composites (CBC). To investigate the synergetic effects, mixtures of $\mathrm{TiO}_{2}$ nanoparticles and carbonized bamboo powder (CBM) were prepared under mass ratios of $1 / 1$ and $2 / 1$, respectively. Benzene and toluene removal efficiencies for $\mathrm{CB}, \mathrm{CBM}$ and $\mathrm{CBC}$ were compared. Removal kinetics was further analyzed by fitting with zero, first, secondorder models, as well as the Elovich equation. Coupled magic angle ${ }^{13} \mathrm{C}$ nuclear magnetic resonance (CPMAS $\left.{ }^{13} \mathrm{C} \mathrm{NMR}\right)$ and energy dispersive elemental analyses were also conducted to further clarify removal mechanisms. 


\section{Methods}

\subsection{Carbonized bamboo (CB) preparations}

Chips ( $100 \mathrm{~mm} \times 50 \mathrm{~mm} \times 5 \mathrm{~mm}$ ) of moso bamboo were oven-dried at $105^{\circ} \mathrm{C}$ for $24 \mathrm{~h}$. They were carbonized up to $600{ }^{\circ} \mathrm{C}$ isothermally for $60 \mathrm{~min}$ under nitrogen gas flow $\left(500 \mathrm{~mL} \mathrm{~min}{ }^{-1}\right)$. The heating rate was increased at $10^{\circ} \mathrm{C} \mathrm{min}^{-1}$. The carbonized bamboo was then heated again up to $800^{\circ} \mathrm{C}$ at a heating rate of $10^{\circ} \mathrm{C} \mathrm{min}^{-1}$ to obtain bamboo charcoal under carbon dioxide flow $\left(500 \mathrm{~mL} \mathrm{~min}{ }^{-1}\right.$ ). The cooled bamboo charcoal was ground and passed through 140 mesh (i.e., $0.105 \mathrm{~mm}$ ). Carbonized bamboo powder was oven-dried at $120^{\circ} \mathrm{C}$ for $24 \mathrm{~h}$ under vacuum. The carbonized bamboo is denoted as $\mathrm{CB}$.

\subsection{Preparation of $\mathrm{TiO}_{2}$ nanoparticles}

$\mathrm{TiO}_{2}$ nanoparticles were prepared with $200 \mathrm{~mL}$ of $1 \mathrm{M}$ $\mathrm{TiCl}_{4}$ solution placed into a $500-\mathrm{mL}$ beaker, with $\mathrm{pH}$ adjusted by $4 \mathrm{M}$ ammonia solution to 1.5 until $\mathrm{TiO}_{2}$ was precipitated. $\mathrm{TiO}_{2}$ precipitates were separated by $11-\mu \mathrm{m}$ cellulose filters (Whatman Qualitative filter papers grade \#1). The $\mathrm{TiO}_{2}$ precipitates thus obtained were washed five times by double deionized water (DDW) and directly dried on the cellulose filter. Then $3 \mathrm{~g}$ of $\mathrm{TiO}_{2}$ dry powder was suspended into $300 \mathrm{~mL}$ of DDW, with $2 \mathrm{~mL}$ of concentrated $\mathrm{HCl}$ added to dissolve $\mathrm{TiO}_{2}$ gel with suspension $\mathrm{pH}$ maintained at 1.5 . The solution was stirred at $50{ }^{\circ} \mathrm{C}$ for $6 \mathrm{~h}$. These conditions are able to transform $\mathrm{TiO}_{2}$ gel into anatase of nanoparticle size (Bruckner et al., 1997). To stabilize $\mathrm{TiO}_{2}$ nanoparticles, citric acid was added to adjust to neutral $\mathrm{pH}$ at the ratio citric acid/Ti of $0.3 \%(\mathrm{w} / \mathrm{w})$ (Hidber et al., 1997). The $\mathrm{pH}$ of suspension was adjusted by $1 \mathrm{M} \mathrm{NaOH}$ to get suspension in neutral $\mathrm{pH}$ of $\mathrm{TiO}_{2}$ nanoparticles. The solid content of $\mathrm{TiO}_{2}$ in suspension was $1 \%$.

\subsection{Preparation of carbonized bamboo (CB), mixture $(\mathrm{CBM})$, composite $(\mathrm{CBC})$ with $\mathrm{TiO}_{2}$ nanoparticles}

First, $10 \mathrm{~g}$ of carbonized bamboo (CB) powder were mixed with different amounts of $\mathrm{TiO}_{2}$ nanoparticles, stirred overnight at $25^{\circ} \mathrm{C}$ and stirring rate of $400 \mathrm{rpm}$, and then diluted to $1 \mathrm{~L}$ by DDW. The weight ratios of $\mathrm{CB}$ to $\mathrm{TiO}_{2}$ were $1: 1$ and 1:2, respectively. The suspension was centrifuged at $21,400 \times g$ for 20 min to separate the mixed materials. After removal of the supernatant, the mixed materials were then oven-dried at $120^{\circ} \mathrm{C}$ for $24 \mathrm{~h}$ under vacuum. The carbonized bamboo mixed with different amounts of $\mathrm{TiO}_{2}$ was named as CBM1 (Ti/CB $=1: 1)$ and CBM2 (Ti/ $\mathrm{CB}=2: 1)$.

The CMB prepared as above-mentioned was reheated to $600{ }^{\circ} \mathrm{C}$ isothermally for $100 \mathrm{~min}$ under nitrogen gas flow $\left(500 \mathrm{~mL} \min ^{-1}\right.$ ). The calcined bamboo charcoal was then oven-dried at $120^{\circ} \mathrm{C}$ for $24 \mathrm{~h}$ under vacuum. Then, the $\mathrm{CB} /$ nanoparticles of $\mathrm{TiO}_{2}$ composite materials were named as $\mathrm{CBC}$. The $\mathrm{CBC}$ containing different amounts of $\mathrm{TiO}_{2}$ was also denoted as $\mathrm{CBC} 1$ and $\mathrm{CBC}$. The capabilities and efficiencies of carbonized bamboo (CB), mixture (CBM) and composite (CBC) for removal of benzene and toluene were compared.

\subsection{Characteristic and morphology of $C B, C B M$ and $C B C$ materials}

The particle size of $\mathrm{TiO}_{2}$ precipitates was determined using Malvern Zeta-Sizer 3000 and identified by X-ray diffraction (XRD) using Rigaku Geigerflex X-ray diffractometer. The CB, CBM and $\mathrm{CBC}$ materials were examined by a JOEL scanning electron microscope coupled with energy dispersive X-ray spectrometer (EDS) (JSM-6500F). Organic functional groups of untreated bamboo (UB) $(<0.105 \mathrm{~mm}$ in size $)$ and carbonized bamboo (CB) were examined by coupling magic angle ${ }^{13} \mathrm{C}$ nuclear magnetic resonance spectroscopy (CPMAS ${ }^{13} \mathrm{C}$ NMR), using a Bruker DSX 400WB NMR instrument. Samples were spun at the magic angle in the boron nitride rotor with a Kel-F cap. The NMR spectra were divided into the following chemical shift regions: alkyl-C (0-45 ppm), $N$-alkyl-C (46-65 ppm), $O$-alkyl-C (65-90 ppm), acetal-C (90-110 ppm), aromaticC (110-140 ppm), phenolic-C (140-160 ppm) and carboxylC (16-200 ppm) (Oades, 2006). The phenolic C contents were calculated from O-substituted aromatic C (Baldock et al., 1992). The contents of different organic carbon functional groups were measured by cutting and weighing the areas in different chemical shift regions and expressed as percentages (relative intensities) (Preston et al., 1990).

Brunauer-Emmett-Teller (BET) surface areas of all samples at $77 \mathrm{~K}$ were obtained using Carlo Erba Sorptometer (Model 1990) instrument. All the samples were degassed at $400 \mathrm{~K}$ for $12 \mathrm{~h}$. The instrument used for nitrogen adsorption analysis was NOVA 2200 from Quantachrome Corporation. Infrared studies in the range of $4000-400 \mathrm{~cm}^{-1}$ for as synthesized manganese oxide samples were recorded on Nicolet 380 spectrophotometer. The samples were mixed well with $\mathrm{KBr}$ in 0.5:300 (mg) ratio and then pelletized. Elemental composition $(\mathrm{C}, \mathrm{H}$, $\mathrm{N}, \mathrm{O}$ and $\mathrm{S}$ ) of HAs was determined using dry combustion method by an elemental analyzer (EA, Heraeus VarioELIII), with acetonitrile as standard.

\subsection{Photo-catalytic activities of $C B, C B M$ and $C B C$ materials for benzene and toluene removal}

In order to evaluate the synergistic effects of sorption and the subsequent photo-catalytic activities of the UB, $\mathrm{CB}, \mathrm{CBM}$ and $\mathrm{CBC}$ materials, benzene and toluene removal experiments were conducted in a closed chamber with an ultraviolet (UV) irradiation source, internal recirculation and $0.03 \mathrm{~m}^{3}$ volume. The above setting was to emulate a possible scheme for indoor air pollutant removal. The UV light intensity was $0.5 \mathrm{~mW} \mathrm{~cm} \mathrm{c}^{-2}$ at a wavelength of $365 \mathrm{~nm}$. Benzene and toluene concentrations were detected by GC/FID (SRI 8610 C) with a Quadrex Methyl 
Phenyl 5 column, $150{ }^{\circ} \mathrm{C}$ injector temperature and $250{ }^{\circ} \mathrm{C}$ detector temperature. A sorption experiment was operated for $180 \mathrm{~min}$ and sampled at $30 \mathrm{~min}$ interval for benzene, toluene and their decomposed products. All the sorption experiments were operated under UV irradiation.

Prior to sorption experiments, $5 \mathrm{~g}$ of oven-dried samples (i.e., UB, CB, CBM and CBC) were spread over the glass surface of a plate with an area of $100 \mathrm{~cm}^{2}$ and placed into the chamber. Both benzene and toluene at $45 \mathrm{ppmv}$ were injected and then circulated inside the apparatus at the flow of $1.5 \mathrm{~L} \mathrm{~min}^{-1}$ at room temperature. The carried gas of GC was nitrogen and the flow rate was $10 \mathrm{~mL} \mathrm{~min}{ }^{-1}$, while the ignition gas was hydrogen and the flow rate was $25 \mathrm{~mL} \mathrm{~min}^{-1}$. All measurements were made in triplicates under same humidity.

\subsection{Kinetic models for fitting toluene and benzene sorption}

Triplicate kinetic runs were carried out for each treatment. Sorption data were fitted by the kinetic models, including zero-order, first-order, second-order, and Elovich equations. These four selected models were the differential forms of the general rate equation (Benson, 1960).

Zero order: $[A]=[A]_{0}-k t$

First order: $\ln [A]=\ln [A]_{0}-k t$

Second order: $1 /[A]=1 /[A]_{0}+k t$

Elovich: $q_{t}=(1 / \beta) \ln (\alpha / \beta)+(1 / \beta) \ln t$

where $q_{t}$ is amount of sorbate per unit mass of sorbent at time $t . \alpha$ and $\beta$ are empirical constants. Slope and intercept are $1 / \beta$ and $(1 / \beta) \ln (\alpha / \beta)$, respectively.

\subsection{Statistical analysis}

The linear form of kinetic equations was applied to the sorption data and their goodness-of-fit was evaluated according to the $R^{2}$, level of significance ( $P$-value), and standard error (SE). The comparisons of the maximum monolayer sorption amounts and sorption rate constants were performed using the least significant difference (LSD). The LSD values were calculated using SE and $t$ values at appropriate degrees of freedom at $95 \%$ confidence levels. The LSD values for the rate constants were obtained from the standard error of the slopes for rate equation.

\section{Results and discussion}

\subsection{Characterization of $\mathrm{TiO}_{2}, \mathrm{UB}, \mathrm{CB}, \mathrm{CBM}$ and $\mathrm{CBC}$ materials}

The mean particle size of $\mathrm{TiO}_{2}$ was $28.0 \mathrm{~nm}$ and the $d$ spacing of the $\mathrm{TiO}_{2}$ nanoparticles was $0.352 \mathrm{~nm}$ of an intense anatase peak (JCPDS 21-1272) and the other weak $\mathrm{X}$-ray reflection peaks. Specific surface areas of the $\mathrm{CB}$, CBM2 and CBC2 were $250.7,275.7$ and $286.0 \mathrm{~m}^{2} \mathrm{~g}^{-1}$, respectively.
Table 1

Distribution (\%) of organic carbon functional groups in UB and $\mathrm{CB}$ samples $\left({ }^{13} \mathrm{C}\right.$ NMR)

\begin{tabular}{llllll}
\hline $\begin{array}{l}\text { Sample } \\
\text { code }\end{array}$ & \multicolumn{5}{l}{ Functional group $(\%)$} \\
\cline { 2 - 6 } & $N$-Alkyl-C & $O$-Alkyl-C & Acetal-C & Aromatic-C & Phenolic-C \\
\hline UB & $31.9 \pm 1.6$ & $30.1 \pm 2.7$ & $14.2 \pm 0.4$ & $23.8 \pm 0.4$ & - \\
CB & $31.6 \pm 1.2$ & - & - & $46.3 \pm 3.3$ & $22.1 \pm 1.3$ \\
\hline
\end{tabular}

From ${ }^{13} \mathrm{C}$ NMR analysis, untreated bamboo (UB) contains mainly $N$-alkyl-C (31.9\%), $O$-alkyl-C (30.1\%), acetal$\mathrm{C}(14.2 \%)$ and aromatic-C (23.8\%) (Table 1), CB contains $N$-alkyl-C (31.6\%), aromatic-C (46.3\%) and phenolic-C $(22.1 \%)$. Thus, UB contains more cellulose $(N$-alkyl-C and acetal-C) and hemicellulose ( $O$-alkyl-C) than CB. However, $\mathrm{CB}$ contains more lignin (aromatic-C) and phenolic-C fractions than UB. On the other hand, both UB and CB samples have not presented any alkyl-C of microbial re-synthesis and carboxyl-C components. Thus, most long chain fatty groups were broken when UB was heated at $600^{\circ} \mathrm{C}$ under nitrogen condition. The decomposition of cellulose and hemicellulose in UB was indicated by increased lignin (aromatic-C) and phenolic- $\mathrm{C}$ contents in the $\mathrm{CB}$ sample after $600{ }^{\circ} \mathrm{C}$ heating in a nitrogen gas flow. Thus, we attribute the sorption of benzene and toluene by $\mathrm{CB}, \mathrm{CBM}$ and $\mathrm{CBC}$ to hydrophobic-hydrophobic interaction.

Infrared spectra (IR) of the UB samples show the absorption bands at $1000-700 \mathrm{~cm}^{-1}$ of the $\mathrm{C}-\mathrm{H}$ bond. However, IR spectra of the CB samples show significantly the absorption bands at $1667-1640 \mathrm{~cm}^{-1}$ of $\mathrm{C}=\mathrm{C}$ bond. It is indicated that the UB samples contain more alkyl-C functional groups than the CB samples. The bamboo samples contain higher aromatic- $\mathrm{C}$ after carbonization. These results show the similar trend to those by ${ }^{13} \mathrm{C}$ NMR analysis. Infrared analysis of anatase showed a wide-range spectrometer giving spectra down to $300-200 \mathrm{~cm}^{-1}$ (Farmer, 1974). Infrared spectra of the CBM and CBC samples show a shoulder absorption band at $650 \mathrm{~cm}^{-1}$.

The energy dispersive elemental analysis (EDS) shows that $\mathrm{Ti}$ content of the $\mathrm{CBC} 2$ sample is higher than that of the CBM2 in the mixed samples. The $\mathrm{C}$ contents show the trend of $\mathrm{CB}>\mathrm{CBM} 2>\mathrm{CBC} 2$ while the $\mathrm{O}$ contents show the trend of $\mathrm{CBM} 2 \approx \mathrm{CBC} 2>\mathrm{CB}$. As can be seen, high Ti contents can coat on the surface of $\mathrm{CBC} 2$ and enhance the catalytic capability for high-efficiency removal of benzene and toluene.

Elemental analysis (EA) indicates that the $\mathrm{N}$ and $\mathrm{C}$ contents in the CB is higher than those in the UB samples, however, the $\mathrm{H}$ contents show the reversed trend. Due to carbonization, $\mathrm{CB}$ contains less $\mathrm{H}$ percentages of aromatic functional groups than the UB sample. These results show the similar trend to those by ${ }^{13} \mathrm{C}$ NMR analysis.

\subsection{Benzene and toluene removal by $C B, C B M$ and $C B C$}

Benzene sorption studies show the removal efficiencies of benzene in $180 \mathrm{~min}$ from CB, CBM1, and CBC1 were 

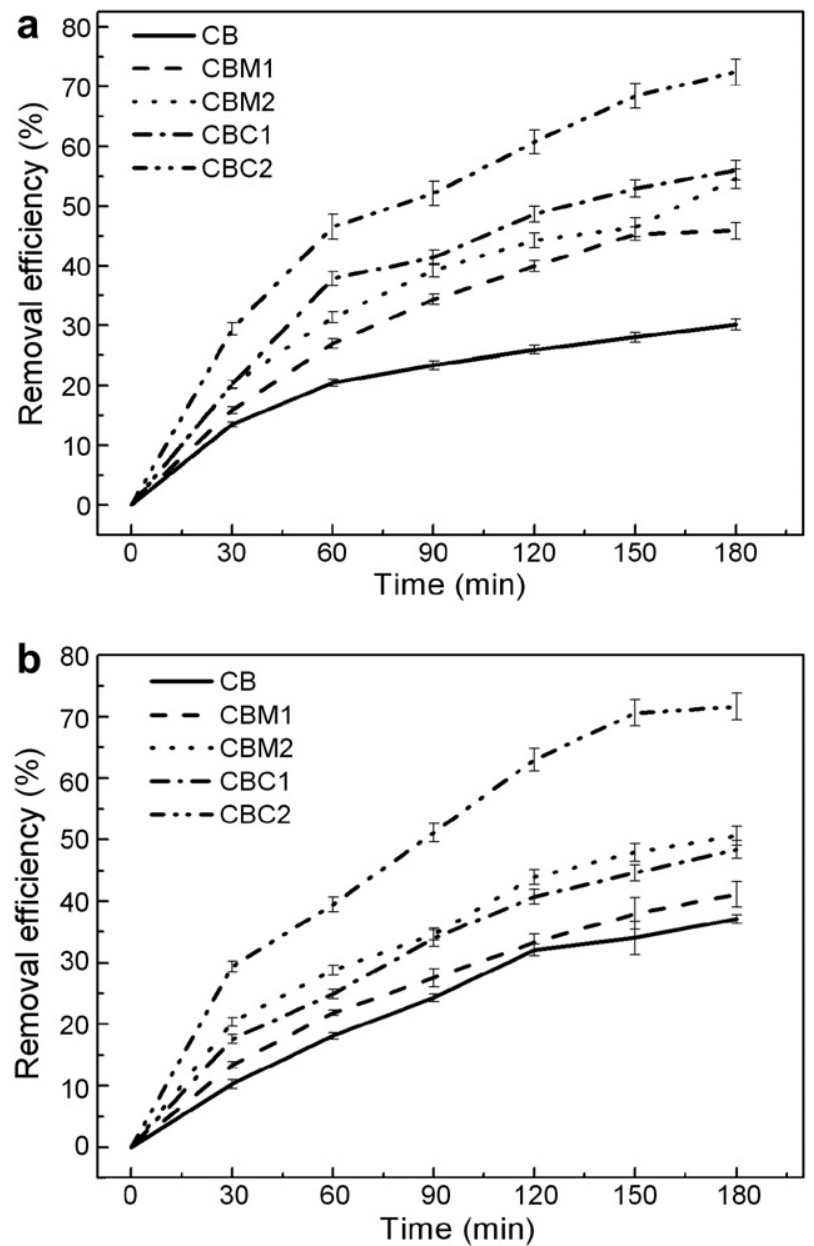

Fig. 1. Benzene (a) and toluene (b) removal efficiencies by CB, CBM1, $\mathrm{CBM} 2, \mathrm{CBC} 1$ and $\mathrm{CBC} 2$.

$30 \%, 45 \%$, and $54 \%$, respectively (Fig. 1a). This indicates that $\mathrm{CBC}$ removed more benzene than the $\mathrm{CB}$ and $\mathrm{CBM}$. On the other hand, $55 \%$ and $72 \%$ of benzene were removed in 180 min from CBM2 and CBC2, respectively. In general, higher $\mathrm{TiO}_{2}$ contents in bamboo (i.e., CBM2, CBC2) can sorb more benzene than those of the $\mathrm{CB}, \mathrm{CBM} 1$ and CBC1 samples.

The CB, CBM1 and $\mathrm{CBC} 1$ samples remove in $180 \mathrm{~min}$ $37 \%, 41 \%$ and $48 \%$ of toluene, respectively (Fig. 1b). However, $\mathrm{CBM} 2$ and $\mathrm{CBC} 2$ can remove in $180 \mathrm{~min} 51 \%$ and $71 \%$ of toluene, respectively. This indicates that higher $\mathrm{TiO}_{2}$ contents are responsible for removing more toluene. The removal efficiency of benzene is slightly higher than that of toluene. Thus, $\mathrm{CBC}$ sorb more benzene and toluene than $\mathrm{CBM}$ and $\mathrm{CB}$, demonstrating that $\mathrm{TiO}_{2}$ enhances benzene and toluene sorption with high catalytic capability. In general, composite materials (i.e., $\mathrm{CBC} 1, \mathrm{CBC} 2$ ) can remove more benzene and toluene than mixed $\mathrm{TiO}_{2}$ and carbonized bamboo (i.e., CBM1, CBM2), and carbonized bamboo $(\mathrm{CB})$ materials.

Under illumination of wavelength $<370 \mathrm{~nm}$, the valence band electron of $\mathrm{TiO}_{2}$ can be excited to the conduction band, creating highly reactive electron-hole pairs. After migration to the solid surface, it can be trapped at different sites. Doi et al. (2000) pointed out that the photo-adsorbed holes are trapped by hydroxyl ions or water on the surface, producing hydroxyl radicals. The mechanism of charge trapping is supported by the fact that the oxygen photoadsorption increases surface hydroxyl concentration and does not take place on completely dry surface. The hole trapping by the hydroxyl species prevents electron-hole recombination at the surface, thus allowing oxygen chemisorption and electron transfer. In general, the removal efficiencies of benzene by $\mathrm{CB}, \mathrm{CBM}$ and $\mathrm{CBC}$ are greater than those of toluene.

\subsection{Kinetic models of toluene and benzene sorption}

The kinetic and empirical equations, including the zero-, first-, and second-order rate equations, and Elovich

Table 2

Statistical analysis of benzene and toluene sorbed by CB, CBM1, CBM2, $\mathrm{CBC} 1$ and $\mathrm{CBC} 2$ and fitted by different kinetic models

\begin{tabular}{|c|c|c|c|c|c|}
\hline & $\mathrm{CB}$ & CBM1 & CBM2 & $\mathrm{CBC} 1$ & $\mathrm{CBC} 2$ \\
\hline \multicolumn{6}{|l|}{ Benzene } \\
\hline Zero order & 0.9338 & 0.9330 & 0.9464 & 0.8701 & 0.9553 \\
\hline First order & 0.8622 & 0.8537 & 0.8868 & 0.7768 & 0.8855 \\
\hline $\begin{array}{l}\text { Second } \\
\text { order }\end{array}$ & 0.7764 & 0.7493 & 0.7997 & 0.6719 & 0.7911 \\
\hline Elovich & 0.9971 & 0.9937 & 0.9856 & 0.9410 & 0.9890 \\
\hline \multicolumn{6}{|l|}{$P$} \\
\hline Zero order & $1.7 \times 10^{-2}$ & $1.7 \times 10^{-3}$ & $1.1 \times 10^{-3}$ & $6.6 \times 10^{-3}$ & $7.6 \times 10^{-4}$ \\
\hline First order & $7.5 \times 10^{-3}$ & $8.5 \times 10^{-3}$ & $5.0 \times 10^{-3}$ & $2.0 \times 10^{-2}$ & $5.1 \times 10^{-3}$ \\
\hline $\begin{array}{l}\text { Second } \\
\text { order }\end{array}$ & $2.0 \times 10^{-2}$ & $2.6 \times 10^{-3}$ & $1.6 \times 10^{-2}$ & $4.6 \times 10^{-2}$ & $1.8 \times 10^{-3}$ \\
\hline Elovich & $3.1 \times 10^{-6}$ & $1.5 \times 10^{-5}$ & $7.79 \times 10^{-5}$ & $1.3 \times 10^{-3}$ & $4.5 \times 10^{-5}$ \\
\hline \multicolumn{6}{|l|}{$S E$} \\
\hline Zero order & $1.4 \times 10^{-2}$ & $2.7 \times 10^{-2}$ & $2.8 \times 10^{-3}$ & $3.8 \times 10^{-2}$ & $2.9 \times 10^{-2}$ \\
\hline First order & $1.0 \times 10^{-3}$ & $1.4 \times 10^{-3}$ & $1.1 \times 10^{-3}$ & $1.5 \times 10^{-3}$ & $9.9 \times 10^{-4}$ \\
\hline $\begin{array}{l}\text { Second } \\
\text { order }\end{array}$ & $6.35 \times 10^{-5}$ & $7.02 \times 10^{-5}$ & $4.8 \times 10^{-5}$ & $5.79 \times 10^{-5}$ & $3.05 \times 10^{-5}$ \\
\hline Elovich & $2.4 \times 10^{-1}$ & $6.9 \times 10^{-1}$ & 1.2 & 2.2 & 1.3 \\
\hline \multicolumn{6}{|l|}{ Toluene } \\
\hline Zero order & 0.9514 & 0.9776 & 0.9701 & 0.9721 & 0.9589 \\
\hline First order & 0.8719 & 0.9085 & 0.9299 & 0.9213 & 0.9245 \\
\hline $\begin{array}{l}\text { Second } \\
\text { order }\end{array}$ & 0.7565 & 0.8015 & 0.8625 & 0.8451 & 0.8672 \\
\hline Elovich & 0.9863 & 0.9866 & 0.9710 & 0.9781 & 0.9651 \\
\hline \multicolumn{6}{|l|}{$P$} \\
\hline Zero order & $8.9 \times 10^{-4}$ & $1.9 \times 10^{-3}$ & $3.0 \times 10^{-4}$ & $2.9 \times 10^{-4}$ & $6.4 \times 10^{-4}$ \\
\hline First order & $6.4 \times 10^{-3}$ & $3.2 \times 10^{-3}$ & $1.9 \times 10^{-3}$ & $2.4 \times 10^{-3}$ & $2.2 \times 10^{-3}$ \\
\hline $\begin{array}{l}\text { Second } \\
\text { order }\end{array}$ & $2.4 \times 10^{-2}$ & $1.6 \times 10^{-2}$ & $7.4 \times 10^{-3}$ & $9.5 \times 10^{-3}$ & $6.9 \times 10^{-3}$ \\
\hline Elovich & $7.03 \times 10^{-5}$ & $6.7 \times 10^{-5}$ & $3.2 \times 10^{-4}$ & $1.8 \times 10^{-4}$ & $4.6 \times 10^{-4}$ \\
\hline \multicolumn{6}{|l|}{$S E$} \\
\hline Zero order & $2.0 \times 10^{-2}$ & $1.4 \times 10^{-2}$ & $1.8 \times 10^{-3}$ & $1.8 \times 10^{-2}$ & $3.1 \times 10^{-2}$ \\
\hline First order & $1.6 \times 10^{-3}$ & $1.1 \times 10^{-2}$ & $8.3 \times 10^{-4}$ & $9.7 \times 10^{-4}$ & $8.7 \times 10^{-4}$ \\
\hline $\begin{array}{l}\text { Second } \\
\text { order }\end{array}$ & $1.2 \times 10^{-4}$ & $7.49 \times 10^{-5}$ & $3.7 \times 10^{-5}$ & $4.87 \times 10^{-5}$ & $2.6 \times 10^{-5}$ \\
\hline Elovich & $9.1 \times 10^{-1}$ & $9.1 \times 10^{-1}$ & 1.5 & 1.3 & 2.4 \\
\hline
\end{tabular}


Table 3

$\alpha$ and $\beta$ values of Elovich equation

\begin{tabular}{llll}
\hline & $\alpha(\%$ benzene $/ \mathrm{min})$ & $\beta(\% \text { benzene } / 1 \mathrm{~g})^{-1}$ & $R^{2}$ \\
\hline Benzene & & & \\
CB & 59.83 & 0.111 & 0.9971 \\
CBM1 & 106.82 & 0.077 & 0.9937 \\
CBM2 & 238.23 & 0.049 & 0.9856 \\
CBC1 & 147.55 & 0.058 & 0.9410 \\
CBC2 & 212.03 & 0.042 & 0.9890 \\
Toluene & & & \\
CB & 258.114 & 0.064 & 0.9863 \\
CBM1 & 215.201 & 0.064 & 0.9866 \\
CBM2 & 184.530 & 0.057 & 0.9710 \\
CBC1 & 276.305 & 0.056 & 0.9781 \\
CBC2 & 276.407 & 0.039 & 0.9651 \\
\hline
\end{tabular}

equations were applied to the benzene and toluene sorption data. The goodness-of-fit of the equation to the data was evaluated by the correlation coefficient $\left(R^{2}\right)$, probability $(P)$, and standard error (SE) of linear regression analysis. The values of these three parameters obtained by applying different models to the kinetic data obtained in the reactions of benzene and toluene adsorption for $\mathrm{CB}, \mathrm{CBM}$ and $\mathrm{CBC}$ are given in Table 2. All the four rate equations fit satisfactorily the benzene and toluene adsorption data. Among the four models tested, the correlation coefficient $\left(R^{2}\right)$ values normalized to the same unit were the lowest for the Elovich kinetic model. More emphasis should be given on the normalized $R^{2}$ value as a criterion for evaluating the model performance, since it is indeed related to the closeness of the model prediction with the observed untransformed data, especially the $\mathrm{SE}$ and $P$-values of four models are similar in these adsorption kinetic experiments.

Showing best correlations, the Elovich equation was chosen as the common model in this study to determine the rate constants. The Elovich kinetic plots for the data are shown in Table 3. The rate of reaction was evaluated by $\alpha$ and $\beta$ values. A high $\alpha$ value and a low $\beta$ value indicate fast reaction rate reaction. In this study, the fast reaction rates of benzene and toluene sorption were by CBM2 and $\mathrm{CBC} 2$, respectively.

\section{Conclusions}

Moso bamboo (UB) has been successfully modified to carbonized bamboo (CB), mixture (CBM) and composite $(\mathrm{CBC})$ with $\mathrm{TiO}_{2}$ nanoparticles. The synergetic effects have been demonstrated by higher removal efficiencies of benzene and toluene from $\mathrm{CBM}$ and $\mathrm{CBC}$ at the same ratio of $\mathrm{Ti} / \mathrm{CB}$. The kinetic data could be well described by the Elovich equation. The modified products demonstrated significantly higher capacity in removal of harmful gases than unmodified materials. This study suggests that the modified products possess high potential of economic values for removing indoor air pollutants and merit further studies.

\section{Acknowledgments}

This work was generously supported by Grant NSC 942113-M-007-039, 91-2313-B-002-361，92-2313-B-002-090, and 93-2313-B-002-008 from the National Science Council, Taiwan and Grant 93AS-2.3.3-E-e2(2) from the Taiwan Forestry Bureau, Council of Agriculture, Taiwan.

\section{References}

Ao, C.H., Lee, S.C., 2004. Combination effect of activated carbon with $\mathrm{TiO}_{2}$ for the photodegradation of binary pollutants at typical indoor air level. J. Photochem. Photobiol. A: Chem. 161, 131-140.

Asada, T., Ishihara, S., Yamane, T., Toba, A., Yamada, A., Oikawa, K., 2002. Science of bamboo charcoal: study on carbonizing temperature of bamboo charcoal and removal capability of harmful gases. J. Health. Sci. 48, 473-479.

Baldock, J.A., Oades, J.M., Waters, A.G., Peng, X., Vassallo, A.M., Wilson, M.A., 1992. Aspects of the chemical structure of soil organic materials as released by solid-state ${ }^{13} \mathrm{C}$ NMR spectroscopy. Biogeochemistry $16,1-42$.

Benson, S.W., 1960. Experimental characterization of simple kinetic systems. The Foundations of Chemical Kinetics. McGraw-Hill Book Co. Inc., New York, pp. 10-83.

Bruckner, H.D., Hamann U., Heyland A., 1997. Photostabilization of Titanium Dioxide Sols. US Patent 5,698,205.

Dagaonkar, M.V., Heeres, H.J., Beenackers, A.A., Pangarkar, V.G., 2003. The application of fine $\mathrm{TiO}_{2}$ particles for enhanced gas absorption. Chem. Eng. J. 92, 151-159.

Doi, M., Saka, S., Miyafuji, H., Goring, D.A.I., 2000. Development of carbonized $\mathrm{TiO}_{2}$ woody composites for environmental cleaning. Mater. Sci. Res. Int. 6, 15-21.

Farmer, V.C., 1974. The anhydrous oxide minerals. In: Farmer, V.C. (Ed.), The Infrared Spectra of Minerals. Mineralogical Society, London, pp. 193-196.

Hidber, P.C., Graule, T.J., Gauckler, L.J., 1997. Influence of the dispersant structure on properties of electrostatistically stabilized aqueous alumina suspensions. J. Eur. Ceram. Soc. 17, 239-249.

Mizuta, K., Matsumoto, T., Hatate, Y., Nishihara, K., Nakanishi, T., 2004. Removal of nitrate-nitrogen from drinking water using bamboo powder charcoal. Bioresour. Technol. 95, 255-257.

Mor, S., Ravindra, K., Bishnoi, N.R., 2006. Adsorption of chromium from aqueous solution by activated alumina and activated charcoal. Bioresour. Technol. 98, 954-957.

Oades, J.M., 2006. Recent advances in organominerals interactions: implication for carbon cycling and soil structure. In: Huang, P.M., Berthelin, J., Bollag, J.M., McGill, W.B., Pages, A.L. (Eds.), Environmental Impact of Soil Component Interactions, Natural and Anthropogenic Organics, vol. 1. CRC Press/Lewis Publishers, Boca Raton, FL, pp. 119-134.

Preston, C.M., Sollins, P., Sayer, B.G., 1990. Changes in organic compounds for fallen logs in old-growth Douglas-fir forests monitored by ${ }^{13} \mathrm{C}$ nuclear magnetic resonance spectroscopy. Can. J. For. Res. 20, 1382-1391.

Qourzal, S., Assabbane, Y., Ichou, A., 2004. Synthesis of $\mathrm{TiO}_{2}$ via hydrolysis of titanium tetraisopropoxide and its photocatalytic activity on a suspended mixture with activated carbon in the degradation of 2 naphthol. J. Photochem. Photobiol. A: Chem. 163, 317-321.

Sarin, V., Pant, K.K., 2006. Removal of chromium from industrial waste by using eucalyptus bark. Bioresour. Technol. 97, 15-20.

Wang, W., Chiang, L.W., Ku, Y., 2003. Decomposition of benzene in air streams by UV/TiO 2 process. J. Hazard. Mater. B101, 133-146. 